\title{
Efficient Biodiesel Production from Algae Oil Using Ca-Doped ZnO Nanocatalyst
}

Esraa Abdala, Omer Nur and Mustafa A. Mustafa

The self-archived postprint version of this journal article is available at Linköping University Institutional Repository (DiVA):

http://urn.kb.se/resolve?urn=urn:nbn:se:liu:diva-172090

N.B.: When citing this work, cite the original publication.

Abdala, E., Nur, O., Mustafa, M. A., (2020), Efficient Biodiesel Production from Algae Oil Using CaDoped ZnO Nanocatalyst, Industrial \& Engineering Chemistry Research, 59(43), 19235-19243.

https://doi.org/10.1021/acs.iecr.oc04118

Original publication available at:

https://doi.org/10.1021/acs.iecr.0c04118

Copyright: American Chemical Society

http://pubs.acs.org/ 


\title{
Efficient Biodiesel Production from Algae Oil Using Ca Doped ZnO Nano Catalyst
}

\author{
Esraa Abdala ${ }^{a}$, O. Nur ${ }^{b}$, Mustafa A. Mustafa ${ }^{c, *}$ \\ ${ }^{a}$ Department of Chemical Engineering, University of Khartoum, Khartoum, Sudan \\ ${ }^{\mathrm{b}}$ Department of Science and Technology, Campus Norrköping, Linkoping University, SE-601 74 Norrköping, Sweden \\ ${ }^{c}$ Materials and Nanotechnology Research Centre, University of Khartoum, Khartoum, Sudan \\ *Email: Dr.Mustafa.Abbas@gmail.com
}

\begin{abstract}
Biodiesel is a sustainable alternative to petroleum diesel produced by trans-esterification of vegetable oils in a presence of a catalyst. The present study investigates heterogeneous transesterification of algal oil to biodiesel using novel calcium doped zinc oxide nanocatalysts synthesized using UV shaker. The developed catalyst was under different light sources UV and non UV, different calcium concentrations $(0.01,0.03,0.05 \mathrm{M})$ and different calcination temperature $\left(600,700,800^{\circ} \mathrm{C}\right)$. The catalyst has been characterized by scanning electron microscope (SEM), X-ray diffraction (XRD), Fourier Transform Infrared spectroscopy (FT-IR), Energy Dispersive Spectra (EDS). The effects of the different parameters used in catalyst preparation were studied for transesterification of algal oil. The catalyst of $0.05 \mathrm{M}$ calcium loading, calcination temperature $700{ }^{\circ} \mathrm{C}$, synthesized in UV light is considered as the most suitable nanocatalyst which achieved $99.18 \%$ yield of biodiesel. The catalyst was used three times effectively with $76 \%$ yield. The chemical properties of biodiesel have been investigated using Gas Chromatography (GC). Keywords: Algae oil; Biodiesel; calcium doped zinc oxide; oil extraction; transesterification
\end{abstract}

\section{Introduction}

Renewable energy sources such as biofuels are considered a key to reducing reliance on the petroleum fuels and the lowering of the impact of greenhouse emissions, specially carbon dioxide and methane, as well as meeting rural development goals ${ }^{1}$. Biodiesel has been shown to be a viable alternative to petroleum diesel. This fuel has properties that are similar to those of diesel oil and can be applied directly in diesel engines without modification to achieve similar performance ${ }^{2,3}$. Along with renewability and biodegradability ${ }^{2}$.

Biodiesel is derived from renewable sources such as vegetable oils and animal fats. It consist of mono-alkyl esters of long chain fatty acids. Waste cooking oil and Non-edible oils such as Jatropha or 
algae oils are more competitive candidates as feedstock for biodiesel production in comparison to vegetable oil due to their low price ${ }^{4}$.

Microalgae with their high photosynthetic rate, do not compete for food production or arable land and they grow much faster than traditional crops However, the production cost of microalgae as a biofuel feedstock is higher compared to the final yield of the product. In the biodiesel industry, crops with higher oil yield are more preferable. Despite this issue, microalgae remain imperative as a future energy feedstock ${ }^{4-6}$.

Biodiesel is usually prepared by trans-esterification of vegetable oils (triglycerides) with alcohol (methanol or ethanol) in the presence of suitable homogeneous or heterogeneous catalyst (base or acid) to form biodiesel (FAME) and glycerol. Faster rate of reaction is reported when using base catalysts rather than acid catalysts ${ }^{7,8}$.

Homogeneous basic catalysts provide much faster reaction rates than heterogeneous catalysts but the overall cost is not competitive due to separation and purification of the catalysts from the reaction mixture and moreover it leads to soap formation ${ }^{9-11}$. Heterogeneous base catalyst are environmentally benign, reusable, noncorrosive and can easily be separated from the reaction mixture and thus reduces the generation of pollutants ${ }^{4,9}$.

The mechanism of the transesterification reaction with methanol using metal oxides catalyst depends on their structure hence it composed of positive metal ions (cations) which act as Lewis acids and negative oxygen ions (anions) which act as Lewis bases and they have direct effect on the adsorption of methanol. Forming methoxide anions and hydrogen cations as illustrated Figure (1). The methoxide anions then react with the triglyceride molecules promoting transesterification reaction to yield methyl esters as shown Figure (2).. ${ }^{12-14}$. Heterogeneous Nano structure metal oxide catalysts have become more preferable for transesterification reactions due to their high catalytic activity, high stability, ease of separation from products and high yield of the reaction product ${ }^{4}$.

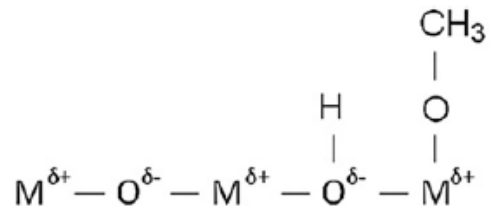

Figure (1) :Surface structure for metal oxide 


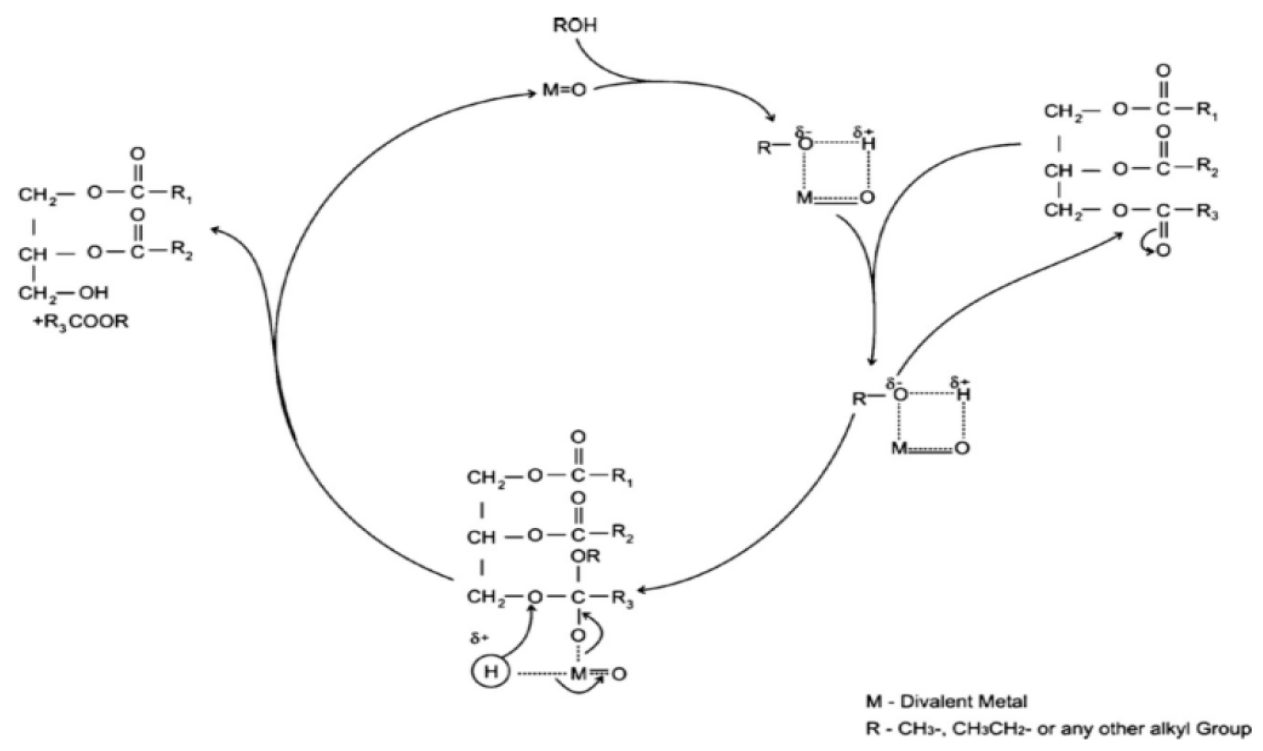

Figure (2) Reaction Mechanism for Basic Metal Oxide Catalyzed Biodiesel Reaction

Zinc oxide can be used as a catalyst since it is cheap, stable, re-usable, commercially available and environmentally benign ${ }^{10}$.However, due to its low basicity and catalytic activity ${ }^{15}$, it can be used as a support with alkaline metals or doped with other metal oxide to originates a good basic solid catalyst and to improve the catalytic activity for the transesterification of vegetable oils ${ }^{10}$. On the other hand, calcium oxide possess a high catalytic activity and basic strength. However, it undergoes leaching which influence the quality of the product. Previous studies have demonstrated the use of a combination of $\mathrm{CaO}$ with other metal oxides to provide higher yield of FAME ${ }^{8,16}$.

Several authors have studied the transesterification reactions of vegetable oil using heterogeneous catalysts. However, limited literature exists on the transesterification of algae oil which was reviewed by ${ }^{17}$. Table (1) summarize the transesterification of algal oil using calcium oxide as heterogeneous catalyst. Currently, no literature is reported in the biodiesel production using zinc oxide solely or doped with different metals for transesterification reaction of algae oil. 
Table 1: Transesterification of algal oil using calcium oxide catalyst

\begin{tabular}{|c|c|c|c|c|}
\hline Feedstock & Catalyst & Optimization Reaction condition & Conversion & References \\
\hline $\begin{array}{l}\text { Mixed } \\
\text { Algae }\end{array}$ & $\begin{array}{l}\mathrm{CaO}: \mathrm{TiO} \\
\text { Calcined at } 700\end{array}$ & $\begin{array}{l}\text { Methanol:oil } 15.68: 1 \\
\text { Catalyst loading } 5.12 \% \mathrm{wt} \\
\text { time } 8.5 \mathrm{hrs} \text { at } 50{ }^{\circ} \mathrm{C}\end{array}$ & $86.4 \%$ & 18 \\
\hline $\begin{array}{l}\text { Mixed } \\
\text { Algae }\end{array}$ & $\mathrm{CaO}$ & $\begin{array}{l}\text { Methanol : oil } 9: 1 \\
\text { catalyst loading rate } 1.5 \% \text { (wt.) } \\
\text { Temp. } 60{ }^{\circ} \mathrm{C}\end{array}$ & $96 \%$ & 19 \\
\hline $\begin{array}{l}\text { Chlorella } \\
\text { vulgaris }\end{array}$ & $\begin{array}{l}\mathrm{KF} / \mathrm{CaO} \text { with } \\
\text { different } \mathrm{KF} \\
\text { loadings }\end{array}$ & $\begin{array}{l}\text { Ultra sound-microwave radiation } \\
\text { methanol :oil 8:1 } \\
\text { catalyst } 12 \% \text { wt Time } 60 \mathrm{~min}\end{array}$ & $93.07 \%$ & 20 \\
\hline $\begin{array}{l}\text { Micro } \\
\text { Chlorella } \\
\text { Vulgaris }\end{array}$ & $\mathrm{CaOAl}_{2} \mathrm{O}_{3}$ & $\begin{array}{l}\text { Methanol: oil volumetric ratio }(3.2: 10) \\
\text { catalyst } 1.56 \% \mathrm{w} / \mathrm{w} \\
\text { Time } 125 \mathrm{~min} \text { temperature of } 50^{\circ} \mathrm{C}\end{array}$ & $88.89 \%$ & 21 \\
\hline
\end{tabular}

Nowadays there is an essential need to develop an effective and inexpensive nanocatalysts with an environmentally benign process ${ }^{8}$. Thus in this research a nanocatlayst calcium doped zinc oxide was designed using co-precipitation method in incubator shaker under different light sources with different loading of calcium and the obtained catalyst was calcined at different temperatures. This work investigates the effect of these conditions used during the synthesis on the catalytic performance for biodiesel production from algae oil. The main factors affecting transesterification reactions are molar ratio of glycerides to alcohol, catalysts, reaction temperature and time ${ }^{22}$. Therefore, the same transesterification reactions conditions were applied for all the catalysts to study the effectiveness of the catalysts and its reusability.

\section{Materials and methods:}

\subsection{Feedstock preparation:}

The algal biomass was collected from the Fish Research Center (Sudan). The utilization of pond water algae that grows naturally in fish ponds in the presence of nutrients available for the fish is expected to reduce the overall cost of biodiesel production from algae oil than using single culture algae. The algae was cleaned many times with distilled water and left to dry under sun for three days followed by drying in oven at $60{ }^{\circ} \mathrm{C}$ and pulverization. The extraction of the oil from the algae powder was conducted using hexane and ethanol solvents with 3:1 ratio followed by mixing and stirring in $350 \mathrm{rpm}$ at $50{ }^{\circ} \mathrm{C}$. The 
higher yield of extractable liquids from algae was achieved by repeating the above-mentioned process many times. The oil was separated form solvents by using rotary evaporator. The value of free fatty acid (FFA) of the microalgae oil was determined $2.93 \%$ using titration with $\mathrm{KOH}$ and the yield of algae lipids was calculated from the weight of algae oil using equation (1) ${ }^{23}$.

$$
\text { Lipid yield }=\frac{\text { Weight of oil }}{\text { Weight of raw material }} \times \quad 100 \%
$$

\subsection{Synthesis of the catalyst:}

All materials with analytical purity (99.9\%) were purchased from Sigma Aldrich. The calcium doped zinc oxide $(\mathrm{CZO})$ nano catalyst were synthesized by co-precipitation method. A stoichiometric amount of the precursors zinc nitrate $\mathrm{Zn}\left(\mathrm{NO}_{3}\right)_{2} \cdot 6 \mathrm{H}_{2} \mathrm{O}$ and different concentrations of calcium nitrate $\mathrm{Ca}\left(\mathrm{NO}_{3}\right)_{2} .4 \mathrm{H}_{2} \mathrm{O}(0.01,0.03,0.05 \mathrm{M})$ were completely dissolved in deionized water and mixed with aqueous solution of sodium hydroxide $(\mathrm{NaOH})$ and subsequently stirred vigorously at room temperature with magnetic stirrer for $15 \mathrm{~min}$ to achieve complete dissolution. The $\mathrm{pH}$ of the solution was maintained between 11 and 12. The mixture was agitated in incubator shaker at $200 \mathrm{rpm}$ for 2 hours at $45^{\circ} \mathrm{C}$. The reaction was influenced by UV light and without using UV light, and then the precipitate formed was centrifuged and washed several times with deionized water to remove impurities. This was followed by drying in an oven at $120^{\circ} \mathrm{C}$ for $120 \mathrm{~min}$. The yielded nanoparticles catalyst were then calcined at different temperatures $\left(600,700,800^{\circ} \mathrm{C}\right)$. The identification of catalysts that were prepared under UV radiation was $0.01 \mathrm{CZO}_{\mathrm{Uv}}, 0.03 \mathrm{CZO}_{\mathrm{Uv}}, 0.05 \mathrm{CZO}_{\mathrm{Uv}}$ and the ones prepared without using UV light as $0.01 \mathrm{CZO} \mathrm{O}_{\mathrm{NUV}}$, $0.03 \mathrm{CZO}_{\mathrm{NUV}}, 0.05 \mathrm{CZO}_{\mathrm{NUV}}$.

\subsection{Catalyst Characterization:}

The average crystalline size and the phase structure of the obtained powders of $\mathrm{Ca}$ doped $\mathrm{ZnO}$ nanoparticles (precursor) were studied by X-ray diffraction analysis (XRD) using a SHIMADZU (XRD 7000 model) instrument with $\mathrm{Cu}$ - Ka radiation $\left(1 \frac{114}{1.5418} \AA\right.$ ) in the $2 \theta$ range from 5 to 85 degrees with 0.02 increments. The peaks in the XRD patterns were indexed using ICDD 36e1451.The average crystallite size was calculated using Scherrer's equation (2) ${ }^{24}$ 
$D=\frac{0.89 \lambda}{\beta \cos \theta}$

where $D$ is the crystallite size, 0.89 is Debye-Scherrer constant, $\lambda$ represent the X-ray wavelength used; $\beta$ is the full line width at the half-maximum height of the main intensity peak, and $\theta$ is the Bragg angle .

The surface morphologies, structure and size distribution of the agglomerates of the obtained samples was observed using an ultra-High-Resolution Scanning Electron Microscope (HRSEM) (HRSEM, Hitachi S4100). The purity of the sample was tested by Energy Dispersive Spectroscopy (EDS). The UV-vis absorption spectra of the samples were recorded in the wavelength range of 200 to $800 \mathrm{~nm}$ at room temperature using a Shimadzu UV 3600 to study the optical band gap properties of the calcium doped $\mathrm{ZnO}$ samples and determining the absorption using Gaussian function. The energy band gap $\left(\mathrm{E}_{\mathrm{g}}\right)$ were calculated using plotted Tauc plots between $(\alpha h v)^{2}$ and photon energy hv where $\alpha$ is the absorption coefficient of the material, $\lambda$ is the wavelength, $h$ is the Planck's constant, $v$ is the frequency of light and Eg is the band gap energy. The plotted graph plotted extrapolating the linear part of the graph until it meets the $\mathrm{x}$-axis will give the value of the band gap.

\subsection{Transesterification of algal oil :}

The experiment was carried out in a three-neck round bottom flask used a batch process reactor and equipped with a reflux condenser in the middle neck, thermometer in the side neck and placed on a magnetic stirrer. Pre-heating of the algae oil is carried out before the reaction to remove moisture, as well the catalyst was vigorously stirred with methanol $\left(99.5 \%\right.$, commercial grade) at $50^{\circ} \mathrm{C}$ before mixing with algae oil for the transesterification reaction. Once the reaction is completed the catalyst was separated from the reaction mixture by decanting while the mixture is transferred to separating funnel and followed by adding little amount hexane and water for separation. The set up were left undisturbed overnight. Afterward the glycerol and little of the catalyst is withdrawn from bottom as an amber colour phase followed by biodiesel little lighter phase as seen on figure (3). The obtained biodiesel then measured. To study the reusability of the catalyst the used catalyst was washed with ethanol several times and centrifuged for regeneration.

Transesterification reaction was carried out to study the effect of the catalyst preparation conditions on the catalytic performance for biodiesel production. The catalytic activity of the synthesized catalysts using UV radiation ( $\mathrm{CZO}$ Uv) were investigated and compared to the samples prepared without using UV radiation $\mathrm{NUV}(\mathrm{CZ} \mathrm{NUV})$. The reaction conducted for catalyst calcined at $700{ }^{\circ} \mathrm{C}$ with different loading of 
calcium $(0.01,0.03,0.05) \mathrm{CZO}$ to assess the influence of calcium loading on the catalytic performance. And to examine the effect of the calcination temperature the catalyst that produced the higher biodiesel yield was investigated at three different calcination temperatures $\left(600,700,800{ }^{\circ} \mathrm{C}\right)$. The transesterification reaction condition was the same for all the prepared catalysts (methanol: oil $=25: 1$ molar ratio, catalyst dosage 2.9 wt. $\%$ of algae oil, reaction temperature $55^{\circ} \mathrm{C}$ and 3 hours). The FAME yield (wt.\%) was calculated using the equation (3)

$$
\text { Yield }=\quad \frac{\text { Weight of oil biodiesel }(\mathrm{g})}{\text { Weight of oil used }(\mathrm{g})} \quad \mathrm{X} \quad 100 \%
$$

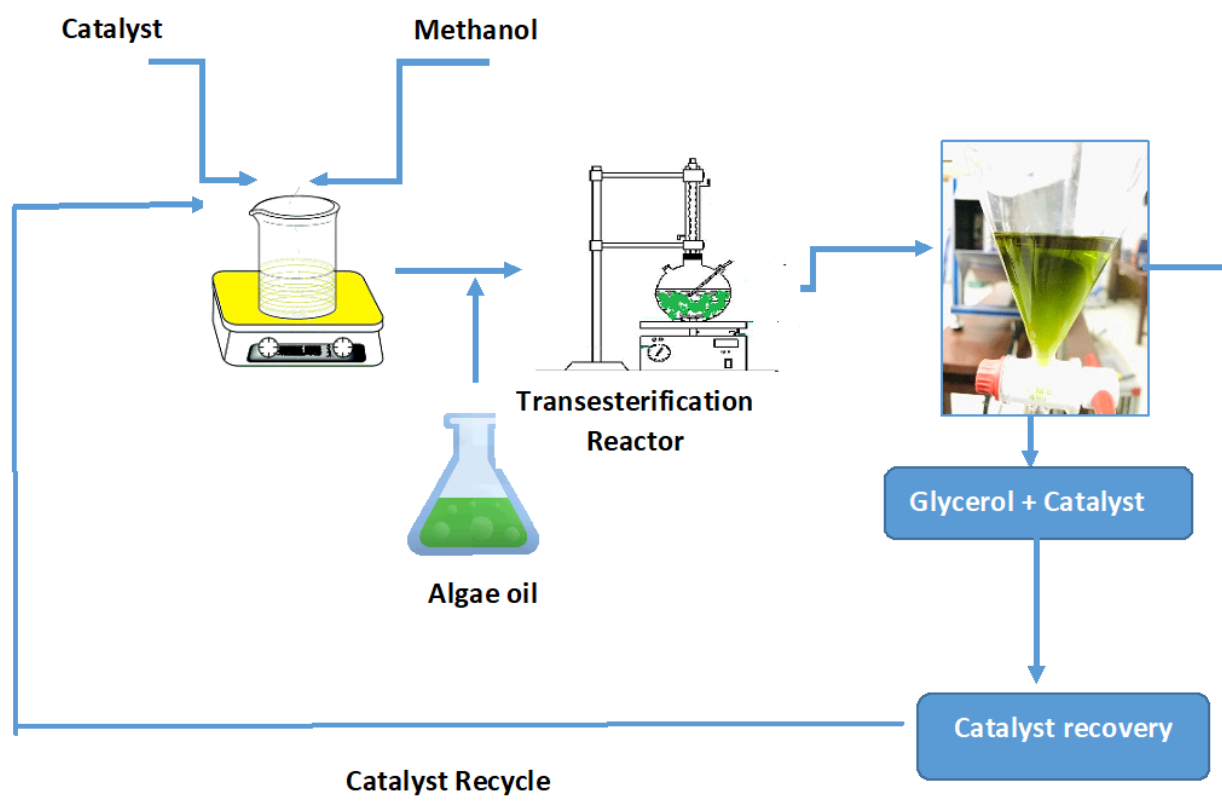

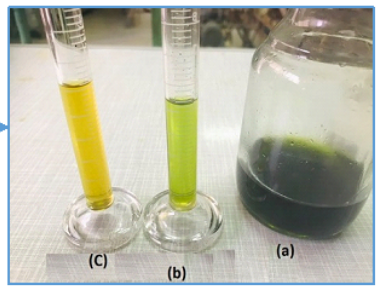

(a) Biodiesel (b) after $1^{\text {st }}$ reuse (c) after $2^{\text {nd }}$ reuse

Figure 3: Schematic flow diagram for Transesterification process

\subsection{Characterization of Algal oil and Biodiesel :}

To validate the adequacy of the biodiesel obtained from transesterification of algae oil both the oil and the biodiesel were characterized for their physical properties such as viscosity, flash point, pour point, fire point and cloud point correspondingly the chemical composition of the biodiesel has been analyzed using GC.

\subsection{Gas chromatography analysis}

The biodiesel were quantified by a Gas hromatography-Mass Spectroscopy (GC-MS QP 2010 Ultra, Shimadzu, Japan ) equipped with fused silica column (30 m x $0.25 \mathrm{~mm}$ x $0.25 \mu \mathrm{m}$ film thickness) and helium was the carrier gas. Briefly, $2 \mathrm{ml}$ of fatty oil was mixed with $7 \mathrm{~mL}$ of alcoholic $\mathrm{NaOH}$ followed 
by addition $7 \mathrm{ml}$ of alcoholic $(1 \% \mathrm{H} 2 \mathrm{SO} 4)$. The mixture was then vortexed for $3 \mathrm{~min}$ and incubated overnight. $2 \mathrm{ml}$ of supersaturated $\mathrm{NaCl}$ solution was added, followed by $2 \mathrm{ml}$ of hexane, the solution then was shaken for 3 minutes and $5 \mu \mathrm{L}$ of the hexane layer was collected and diluted with $5 \mathrm{ml}$ dethyl ether and $1 \mathrm{gm}$ of Sodium sulphate were added as drying agent. The prepared sample then filtered and $1 \mu \mathrm{L}$ were injected in the GC-MS

\section{Results and Discussion:}

\subsection{Characterization of the Catalyst:}

The XRD profile of the all catalyst samples prepared $\mathrm{CZO}_{\mathrm{UV}}$ and $\mathrm{CZO}_{\mathrm{NUV}}$ showed the formation of the hexagonal ZnO wurtzite structure (JCPDS no. 36-1451). All samples showed a high crystalline nature diffraction peaks, no impurities were detected in the XRD patterns, confirming the high purity of the synthesized products.

Figure (4) illustrated the XRD profiles of the $0.05 \mathrm{CZO}_{\mathrm{NUV}}$ calcined under various temperatures $\left(600,700\right.$, and $\left.800^{\circ} \mathrm{C}\right)$. Peaks of $\mathrm{Ca}(\mathrm{OH})_{2}$ and $\mathrm{CaO}$ were detected in all the calcination temperature used this can be attributed to the thermal decomposition of calcium carbonate to form $\mathrm{CaO}$ and $\mathrm{Ca}(\mathrm{OH})_{2}$ or it could be a result from the conversion of some $\mathrm{CaO}$ into $\mathrm{Ca}(\mathrm{OH})_{2}$ when it exposed to the atmosphere, unlike samples prepared by UV (CZOUv) $\mathrm{CaCO} 3$ peaks were detected in low calcination temperature $(600,700){ }^{\circ} \mathrm{C}$ and it was not shown at high calcination temperature $(800)^{\circ} \mathrm{C}$ as shown in Figure (5). From XRD data Figure (6) when comparing using UV light and NUV light for $0.05 \mathrm{CZO}$ calcined at $700^{\circ} \mathrm{C}$ we can observe that the crystallinity of the $0.05 \mathrm{CZO} U \mathrm{~V}$ nanoparticles is superior to that of the $\mathrm{CZO}_{\mathrm{NUV}}$ confirming that UV light acts as important growth factor in agreement with what was reported by ${ }^{25}$ and it acts as an excitation source. Moreover, a slight shift of the XRD peaks towards higher 2-theta degrees was observed when using UV light.

From Scherrer's equation (2) the average crystallite size varies in the range of 33-38 nm for $0.05 \mathrm{CZO}_{\mathrm{UV}}$ and $0.05 \mathrm{CZO}_{\mathrm{NUV}}$ respectively. The size increases with the increase in calcination temperature and a similar trend has also been observed in literature ${ }^{26}$ and slightly with increasing calcium loading. 


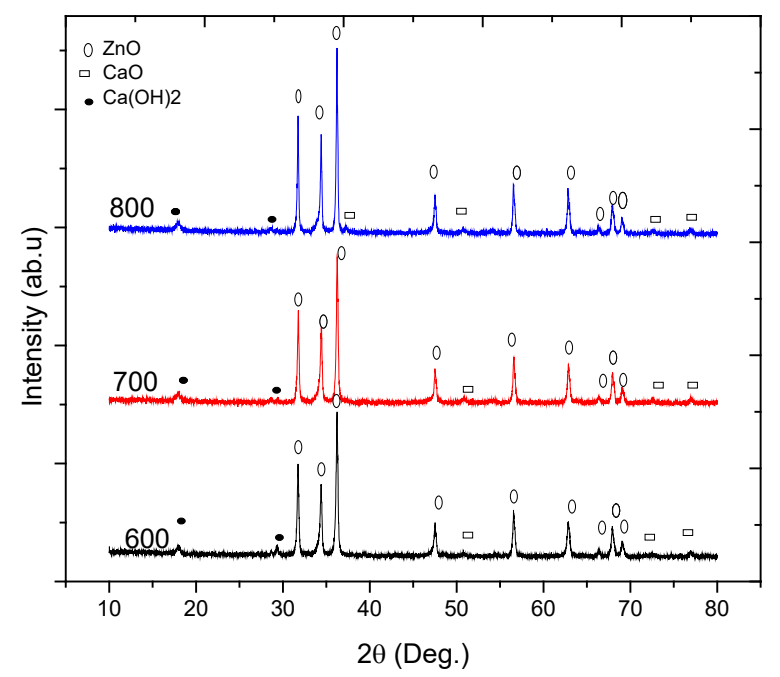

Figure 4: XRD profile of CZONUV 0.05 $\mathrm{M}$ of CZO calcined at different temperatures $600,700,800{ }^{\circ} \mathrm{C}$

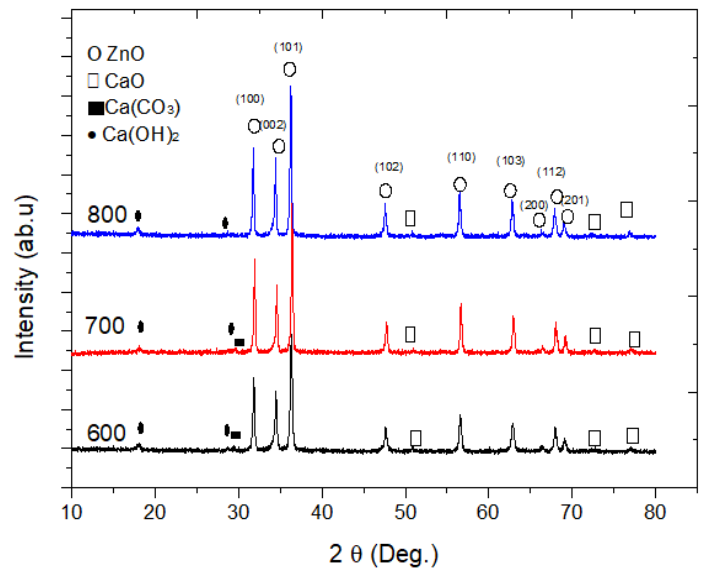

Figure 5: XRD profile of $\mathrm{CZO}_{\mathrm{Uv}} 0.03 \mathrm{M}$ of $\mathrm{CZO}$ calcined at different temperature

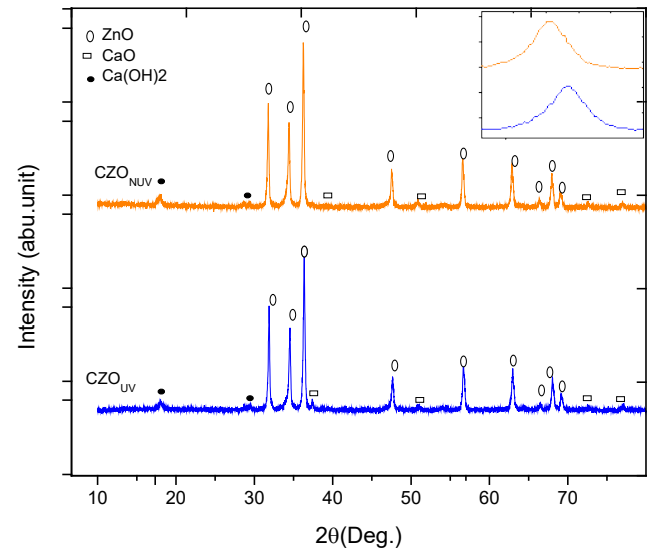

Figure 6: $\mathrm{XRD}$ profile of $0.05 \mathrm{M}$ of $\mathrm{CZO}_{\mathrm{Uv}}$ and $\mathrm{CZO}_{\mathrm{NUv}}$ calcined at $700^{\circ} \mathrm{C}$ 
The HRSEM analysis was used to investigate the morphologies of the CZO nanoparticles. According to the different morphologies obtained, it was clear that the reaction conditions such as light source, calcium loading and calcination temperature, have a great influence on the nanoparticles morphologies.

Figure (7) illustrate the effect of calcium loading in the structure $\mathrm{CZO}_{\mathrm{UV}}$ and $\mathrm{CZO}_{\mathrm{NUV}}(0.01,0.03,0.05)$. The results reveal that most of nanoparticles form a flower like structure. A slightly tall nanoparticles with agglomeration was observed at lower Ca loading and more defined shapes at higher concentrations. Using UV light clearly plays was s a dominant factor on the formation of nano rods and nano spherical particles which was observed at lower concentrations, The effect of the calcination temperature was seen in the colour of the synthesized sample as it was white before calcination and it changed to yellow after it was exposed to $600{ }^{\circ} \mathrm{C}$ calcination temperature and slightly yellow at $700{ }^{\circ} \mathrm{C}$ to white at $800{ }^{\circ} \mathrm{C}$ which confirm the result obtained and by ${ }^{27}$. 

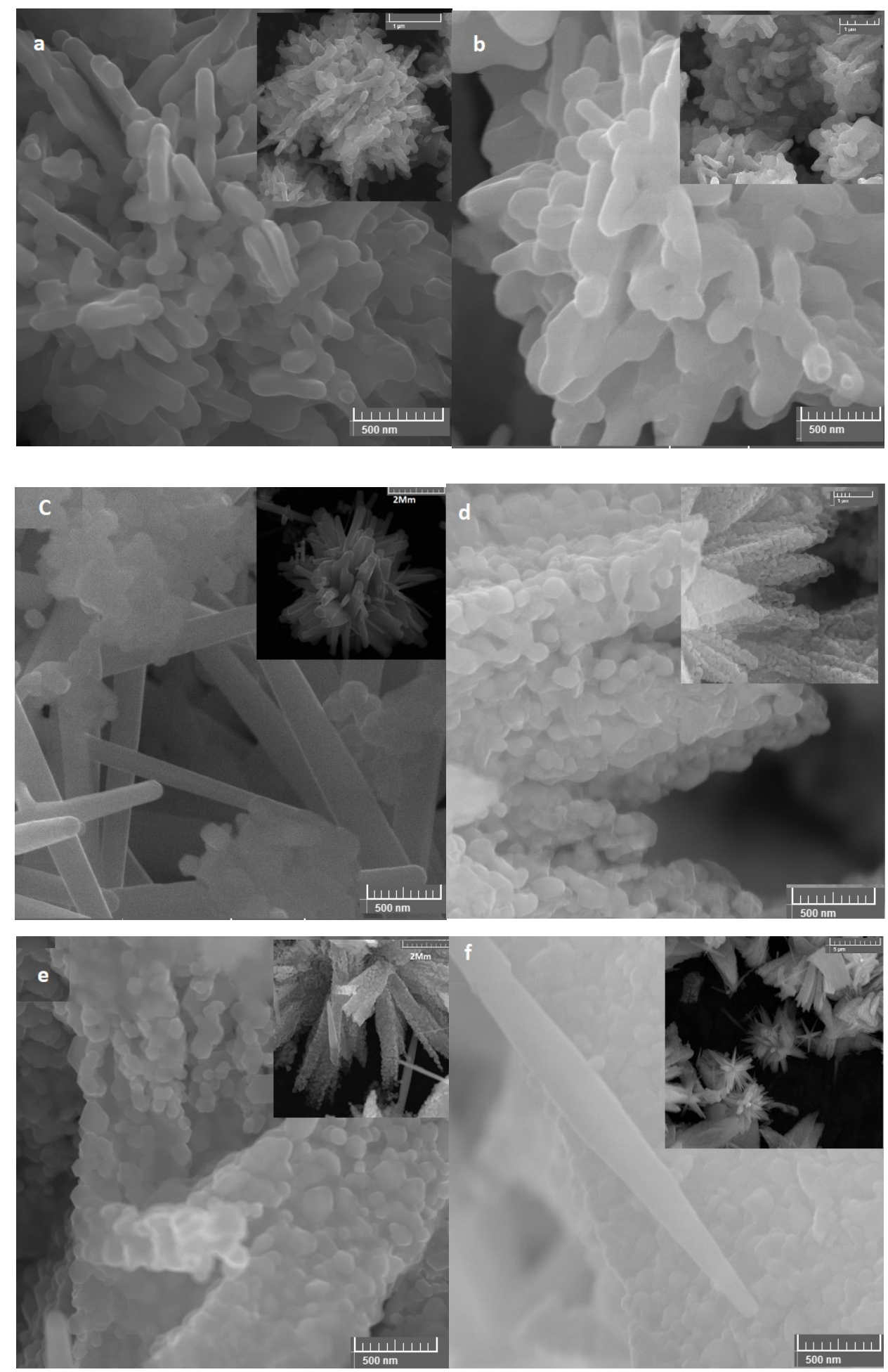

Figure 7: SEM Images (a) $0.01 \mathrm{CZO}_{U \mathrm{Uv}}$ (b) $0.01 \mathrm{CZO}_{\mathrm{NUV}}$ calcined $700^{\circ} \mathrm{C}$, (c) $0.03 \mathrm{CZO}_{U \mathrm{UV}}$ (d) $0.03 \mathrm{CZON}_{\mathrm{UV}}$ (e) $0.05 \mathrm{CZO}_{\mathrm{Uv}}$ (f) $0.05 \mathrm{CZO}_{\mathrm{Nuv}}$ 
Using SEM-EDS analysis the energy dispersive spectra of the catalyst samples $0.05 \mathrm{CZO}_{\mathrm{UV}}$ and CZO $\mathrm{OUV}_{\mathrm{NU}}$ obtained are illustrated in Figure (8) and Figure (9) respectively. It shows clearly the presence of the main elements $\mathrm{Zn}, \mathrm{O}$ and $\mathrm{Ca}$ dopant in the samples.
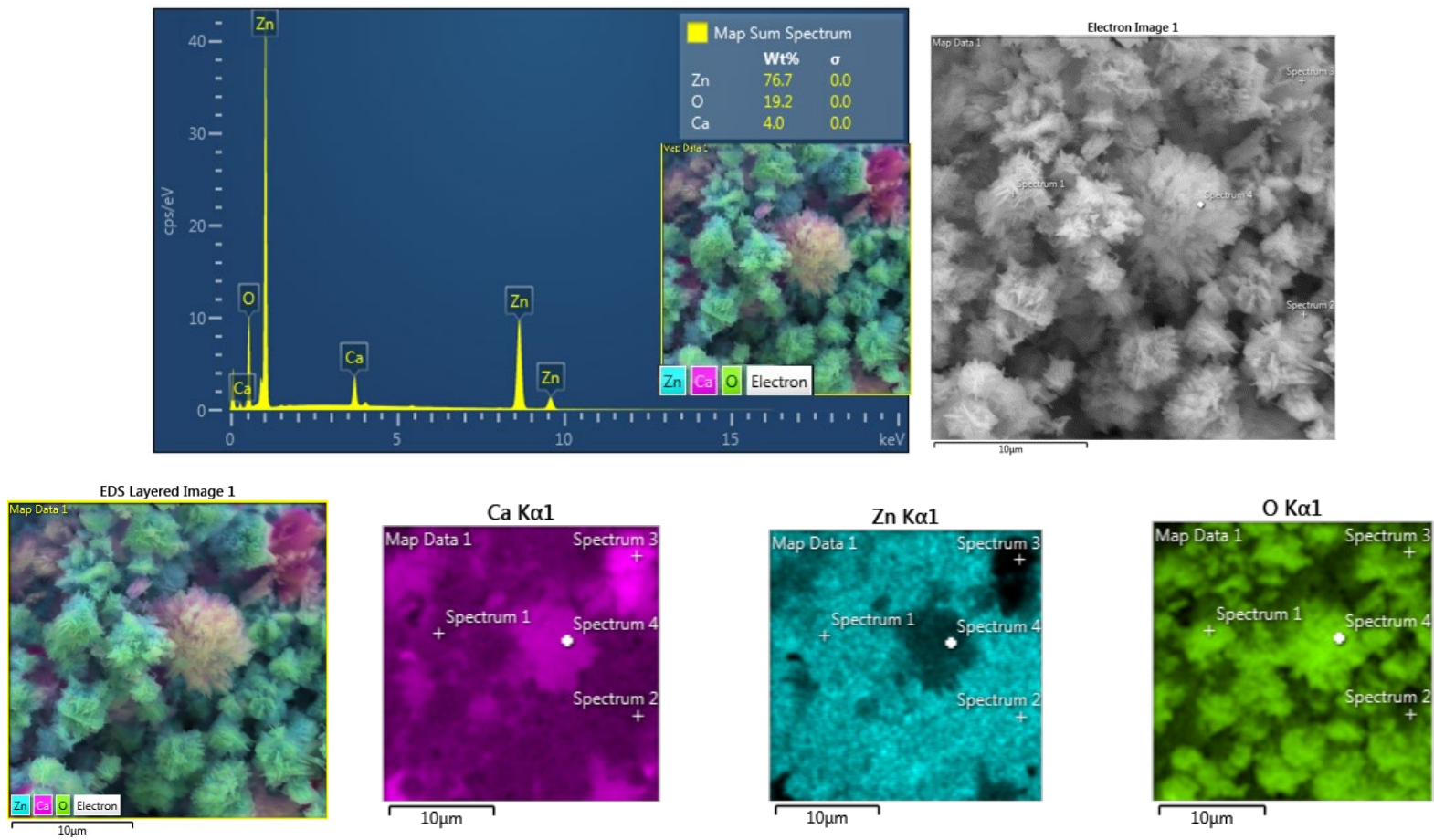

Figure 8: EDS spectrum for $0.05 \mathrm{M}$ of CZOUV Calcined at $700 \mathrm{C}$
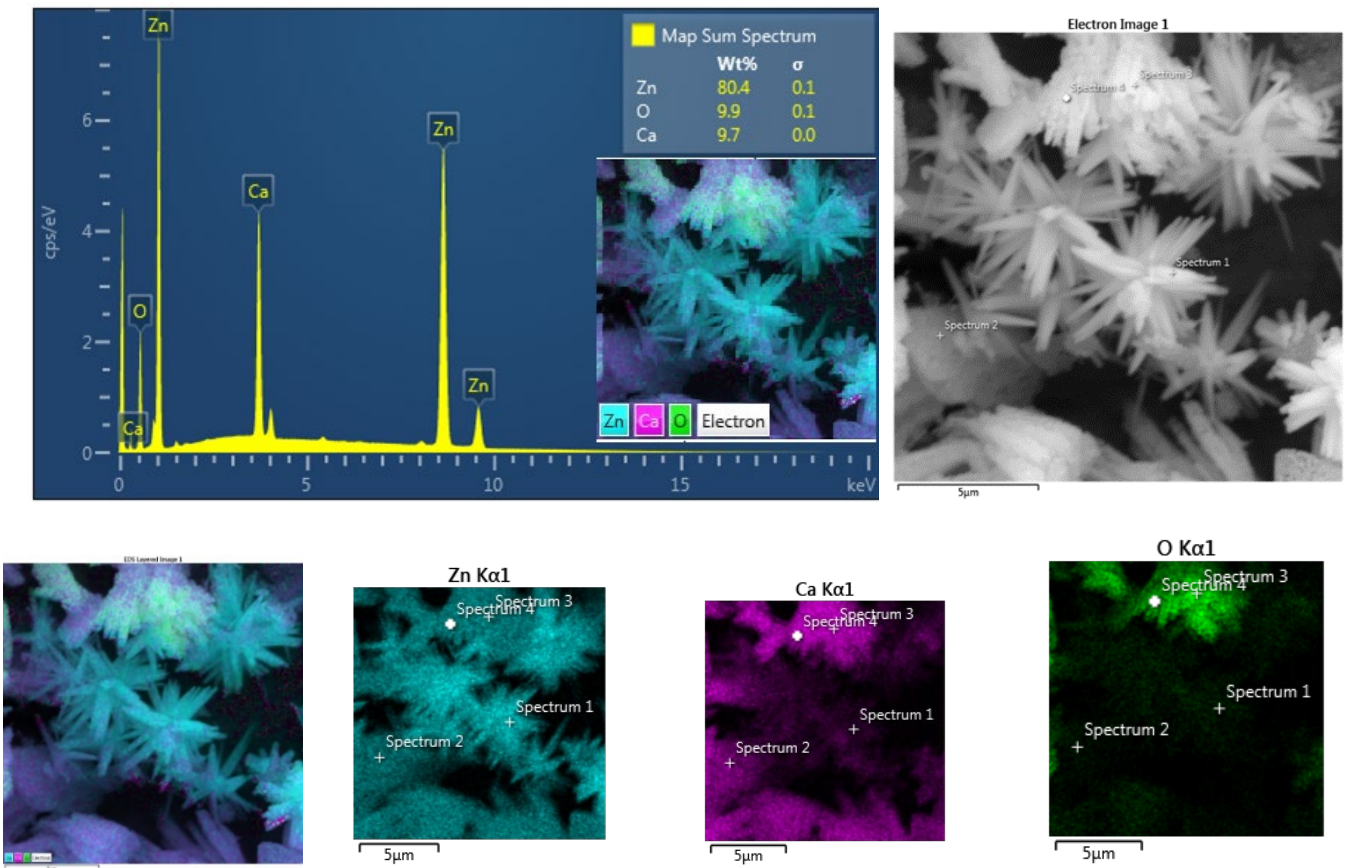

Figure 9: EDS spectrum for $0.05 \mathrm{M}$ of CaZONUV Calcined at $700 \mathrm{C}$ 


\subsection{The Algal oil Characterization}

The algae sample used for transesterification had a 65.86 moisture content, 5.89 ash, 8.26 protein, 9.71 fat and 3.86 fiber for $100 \mathrm{~g}$ algae, the oil yield produced from algae was calculated using equation (3) and it's found $52.4 \%$ of dry weight algae, the oil extracted may contain dyes and other hydrocarbons dissolved in the solvents. The oil obtained had a refracting index 1.361 using refractometer. The analysis of oil is illustrated at table (2).

Table 2: Analysis of Algae Oil

\begin{tabular}{|l|l|l|}
\hline Test Name & Result & Test Method \\
\hline Viscosity & 1.7435 & ASTM D 445 \\
\hline Flash point & $44 \mathrm{C}^{\circ}$ & ASTM D93 \\
\hline Fire Point & $50 \mathrm{C}^{\circ}$ & ASTM D93 \\
\hline Pour Point & $<-8 \mathrm{C}^{\circ}$ & ASTM D2500 \\
\hline Cloud Point & $-5 \mathrm{C}^{\circ}$ & ASTM D97 \\
\hline Appearance & Green & \\
\hline
\end{tabular}

\subsection{Effect of Calcium loading on biodiesel production :}

Figure (10) shows the influence of calcium loading on the catalytic performance for the catalyst that was prepared under UV and NUV, different concentrations of calcium doped in zinc oxide $\mathrm{CaO}: \mathrm{ZnO}(0: 1$, $0.01: 1,0.03: 1,0.05: 1 \mathrm{M}$ ) calcined at $700{ }^{\circ} \mathrm{C}$, were tested for algae oil conversion under the same reaction conditions (methanol : oil $=25: 1$ molar ratio, catalyst dosage $2.9 \mathrm{wt} . \%$ of algae oil , reaction temperature $55^{\circ} \mathrm{C}, 3$ hours). It reveals that when using $\mathrm{ZnO}$ pure as control a low yield of biodiesel was achieved, and when the calcium loading in the catalyst was increased from $0.01 \mathrm{M}$ to $0.03 \mathrm{M}$ the conversion was increased from $89 \%$ to $91 \%$ respectively. The best catalytic performance was achieved at higher content of calcium on catalyst $0.05 \mathrm{M}$ which result in conversion $99 \%$ yield of FAME. The obtained results can be attributed to the high basicity of calcium in comparison zinc. 


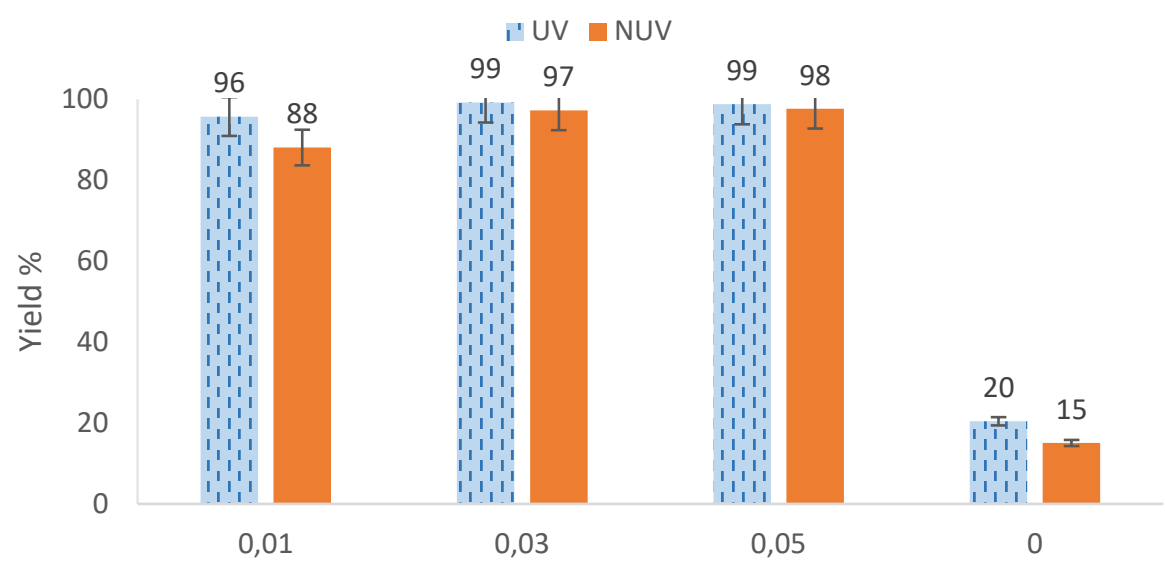

Figure 10: Effect of Ca loading on the catalytic performance of $\mathrm{CZO}_{\mathrm{Uv}}$ and $\mathrm{CZO}_{\mathrm{NUV}}$ for biodiesel production

\subsection{Effect of the catalyst calcination temperature on biodiesel production:}

The specific surface area, morphology and texture of the catalyst are important factors that influence its catalytic performance, and it is directly affected by the calcination temperature that the catalyst is exposed to. Therefore, the effect of the different calcination temperatures $\left(600,700,800^{\circ} \mathrm{C}\right)$ of the $0.05 \mathrm{CZO}$ (UV and NUV) catalysts on the FAME yield were examined at the same conditions of transesterification reaction (methanol: oil $=25: 1$ molar ratio, catalyst dosage $2.9 \mathrm{wt} . \%$ of algae oil , reaction temperature $55^{\circ} \mathrm{C}$ and 3 hours). Figure (11) shows that for $\mathrm{CZO}_{\mathrm{Uv}}$ and $\mathrm{CZO}_{\mathrm{NUV}}$ at $600{ }^{\circ} \mathrm{C}$, the attained yield was 96 $\%$ and $88 \%$. At $700^{\circ} \mathrm{C}$ a higher biodiesel yield was achieved $\mathrm{CZO}_{\mathrm{Uv}}$ and $\mathrm{CZO}_{\mathrm{NUV}} 99 \%$ and $97 \%$ and at $800^{\circ} \mathrm{C}$ the yield $(99 \%, 98 \%)$ for $\mathrm{CZO}_{\mathrm{Uv}}$ and $\mathrm{CZO}_{\mathrm{Nuv}}$ respectively. The difference in the yield between $700{ }^{\circ} \mathrm{C}$ and $800{ }^{\circ} \mathrm{C}$ is minor so using $700{ }^{\circ} \mathrm{C}$ more preferable as calcination temperature for high biodiesel yield production. 


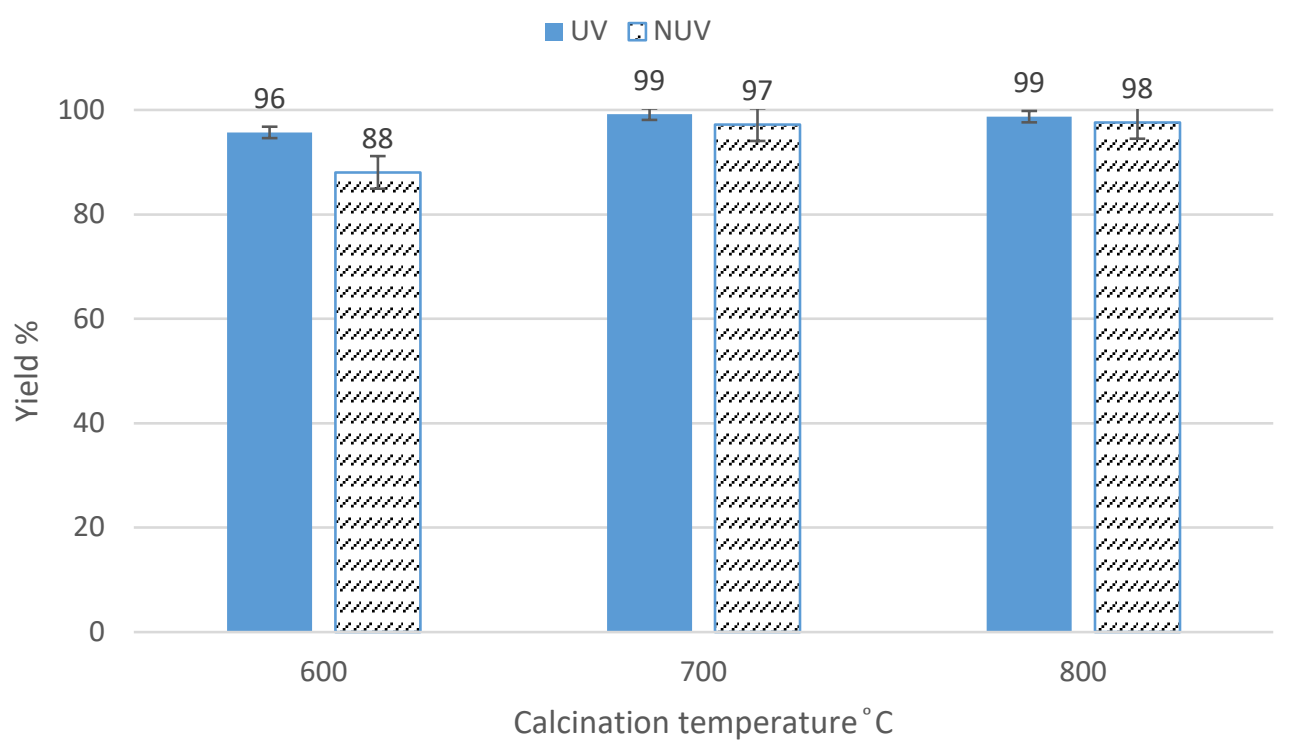

Figure 11: Effect of calcination temperature on the catalytic performance of $\mathrm{CZO}_{\mathrm{Uv}}$ and $\mathrm{CZO}_{\mathrm{NUv}}$ for biodiesel production

\subsection{Effect of light Synthesis on the Catalytic activity :}

The yields of FAME produced via the transesterification of algae oil with methanol over several CZO are summarized in Table (3). It can be seen that samples prepared using UV (CZO $\mathrm{CV}_{\mathrm{UV}}$ ) light produce higher FAME than NUV (CZ $\mathrm{CZ}_{\mathrm{NUV}}$ ) which shows that the light used during synthesis of the catalyst is a crucial parameter on the catalytic performance of $\mathrm{CZO}$ for biodiesel production

Table 3: The yield obtain by different catalysts

\begin{tabular}{|c|c|c|c|}
\hline \multirow{2}{*}{ Catalyst } & \multirow{2}{*}{ Calcination Temp } & \multicolumn{2}{|c|}{ Yield\% } \\
\cline { 3 - 4 } & & \multicolumn{2}{|c|}{ Light used during synthesis } \\
\cline { 2 - 4 } & 600 & 95.69 & NUV \\
\hline \multirow{3}{*}{$\mathbf{C Z O}_{\mathbf{0 . 0 5}}$} & 700 & 99.18 & 88.04 \\
\cline { 2 - 4 } & 800 & 98.71 & 97.19 \\
\hline $\mathbf{C Z O}_{\mathbf{0 . 0 3}}$ & 700 & 91.19 & 97.61 \\
\hline $\mathbf{C Z O}_{\mathbf{0 . 0 1}}$ & 700 & 89.06 & 85.49 \\
\hline $\mathbf{C Z O}_{\mathbf{0 . 0}}$ & 700 & 20.42 & 80.34 \\
\hline
\end{tabular}




\subsection{Catalyst Reusability:}

The most important feature of a heterogeneous catalysts is reusability and stability. The catalyst $0.05 \mathrm{CZO}$ Uv according to the yield achieved was chosen as the optimal catalyst. Therefore, it was recovered and then reused three times for biodiesel production using the same reaction conditions $\left(55^{\circ} \mathrm{C}\right.$, molar ratio methanol: oil 25:1 for 3 hrs.). The catalyst, after each reaction, was cleaned, with ethanol 3 times and then centrifuged and dried before use. The initial amount of catalyst used was $2.9 \mathrm{wt} \%$ catalyst/oil but every repetition there was 1-2 \% loss during separation and washing. As demonstrated in Figure 12 the catalyst can be used three times effectively. The biodiesel yield decreased up to $76 \%$ in the third time. Thereafter, there was a faster rate of reduction in FAME yield in the fourth reuse probably due to the loss of catalytic active components with the leaching of the catalyst during the reaction ${ }^{4}$. After the second use of the catalyst, an obvious lightening of the dark green colour of the biodiesel was noted, and it got more lightened in the third use and in the fourth it was almost yellow. These observation can address the highly efficient adsorption sites in the catalyst, so while the catalytic activity of the catalyst decrease the porosity of the catalyst increase.

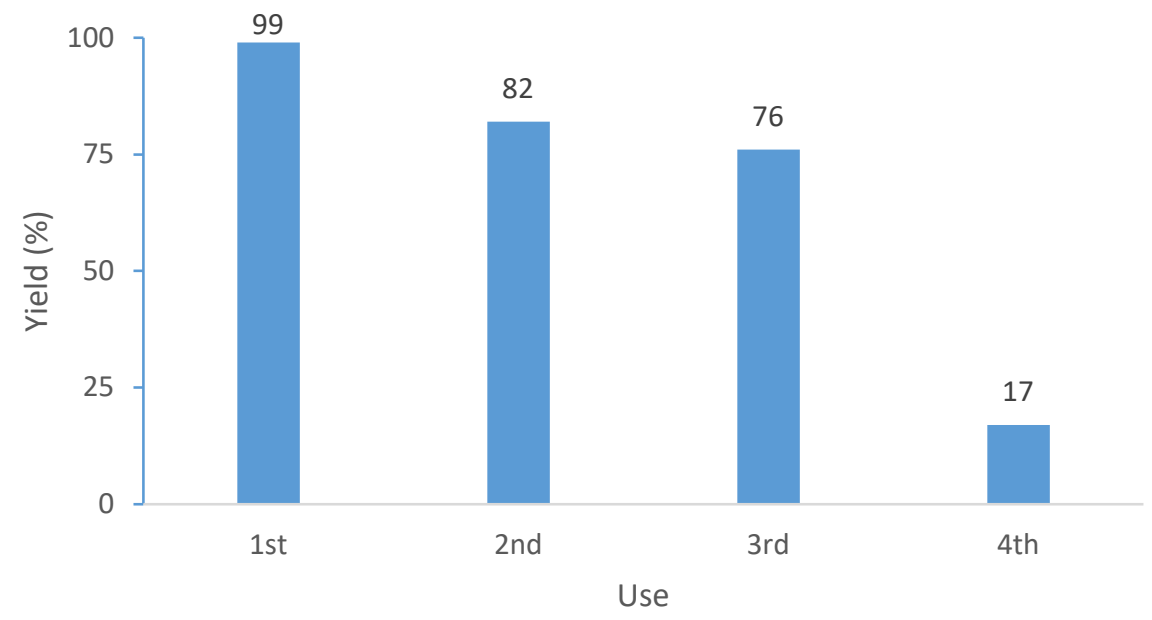

Figure 12: Effect of catalyst regeneration on the catalytic performance of $0.05 \mathrm{CZO}_{\mathrm{uv}}$ for biodiesel production at reaction conditions (methanol: oil $=25: 1$, cat. $2.9 \mathrm{wt} . \%$ oil , $\mathrm{T}=55^{\circ} \mathrm{C}, 3 \mathrm{hrs}$.)

\subsection{Characterization of algae oil and biodiesel produced}

The oil yield produced from algae was calculated using eq 1 and it's found $52.4 \%$ of dry weight. Table 3 tabulates the physical properties of the biodiesel attained by transesterification. The chemical composition was 
analyzed using GC as seen on Figure (14) which showed the presence of C16,C17 and C18 methyl ester and C16 ethyl ester and it were identified using data base library.

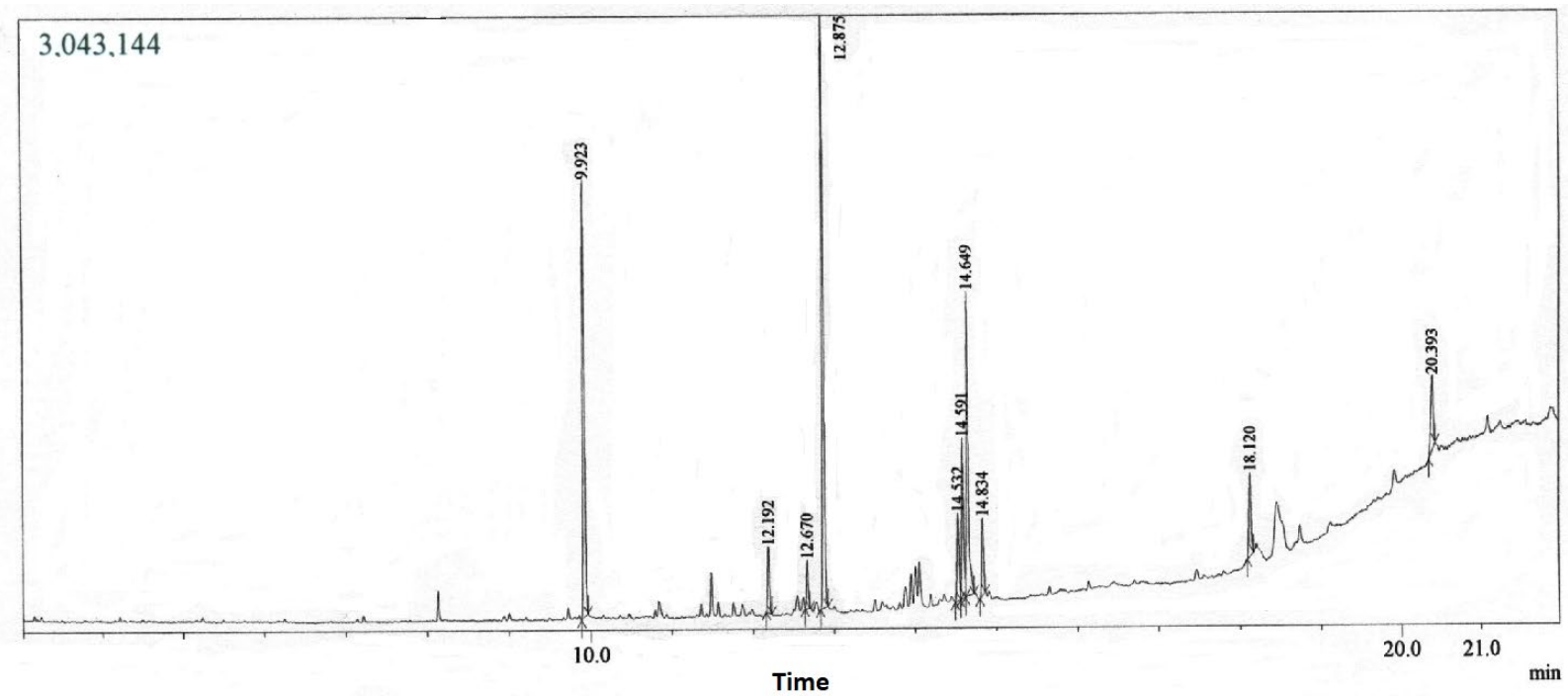

Figure 14: GC MS for algae biodiesel

\subsection{Characterization of algae oil and biodiesel produced:}

The oil yield produced from algae was calculated using eq 1 and it was found to be $52.4 \%$ of dry weight. Table 4 tabulates the physical properties of the biodiesel attained by transesterification.

Table 4: Physical Properties of algae oil and Biodiesel

\begin{tabular}{|l|l|l|l|}
\hline Physical Test & Biodiesel & ASTM for biodiesel & Test Method \\
\hline Flash point & $46 \mathrm{C}^{\circ}$ & Min 93 & ASTM D93 \\
\hline Pour point & $<-6 \mathrm{C}^{\circ}$ & - & ASTM D97 \\
\hline Fire point & $58 \mathrm{C}^{\circ}$ & - & ASTM D93 \\
\hline Cloud point & $-3 \mathrm{C}^{\circ}$ & Max 12 & ASTM D97 \\
\hline Specific Gravity & 0.8166 & - & ASTMD4052 \\
\hline Viscosity at $35^{\circ} \mathrm{C}$ & 1.4 & $1.9-6$ & ASTM D445 \\
\hline Density gm/cm ${ }^{3}$ at $15^{\circ} \mathrm{C}$ & 0.82 & $0.84-0.89$ & \\
\hline API & 47.78 & - & \\
\hline Calorific value $\mathrm{MJ} / \mathrm{Kg}$ & 44.67 & $40-50$ & \\
\hline Refraction index & 1.346 & & \\
\hline
\end{tabular}




\section{Conclusion:}

The present study dealt with mixed species of algae collected from fish farms. The natural water algae biomass is expected to be a cheaper feedstock for biodiesel production as compared to pure cultures of algae. Calcium doped Zinc Oxide CZO demonstrates an efficient nanocatalyst for FAME production from algae oil. The parameters used during nanocatalyst synthesis such as light sources (UV and NUV), calcium loading and calcination temperature have a significant effect on the catalytic performance of the catalyst for biodiesel production. Characterization of the catalyst was performed by XRD, SEM. It was shown that the preparation conditions has a significant effect on the texture, size and morphology of the catalyst. The catalyst showed a high performance, in general, in the transesterification reaction. The highest biodiesel yield achieved was 99\% when using $0.05 \mathrm{CZO}$ of calcium loading and calcination temperature $700^{\circ} \mathrm{C}$. Over all, the best catalytic performance was found for the catalysts prepared under UV light. The operational conditions of the transesterification reaction were $55^{\circ} \mathrm{C}$; catalyst dosage $2.9 \mathrm{wt} \%$ oil;. \% oil; molar ratio methanol: oil, 25:1 for $3 \mathrm{~h}$ using a magnetic stirrer. The catalyst can be used three times effectively and maintain the biodiesel yield up to $76 \%$. The GC MS for the biodiesel showed the presence of C15, C17 and C18 and it has a calorific value of $44.67 \mathrm{MJ} / \mathrm{Kg}$.

\section{Acknowledgement:}

The authors are grateful for the financial support from the Osman Elbashir Research Grant (Prof. Nimir O. Elbashir, Texas A\&M University, Qatar) under the Chemical Engineering Department at the University of Khartoum.

\section{References:}

1. Koh LP, Ghazoul J. Biofuels, biodiversity, and people: Understanding the conflicts and finding opportunities. Biol Conserv. 2008;141(10):2450-2460. doi:10.1016/j.biocon.2008.08.005

2. Nautiyal P, Subramanian KA, Dastidar MG. Production and characterization of biodiesel from algae. Fuel Process. Technol. 2014;120:79-88. doi:10.1016/j.fuproc.2013.12.003

3. Pinnarat T. Noncatalytic esterification for biodiesel production. Univ Micgigan. 2011:1-133.

4. Baskar G, Soumiya S. Production of biodiesel from castor oil using iron (II) doped zinc oxide nanocatalyst. Renew Energy. 2016;98:101-107. doi:10.1016/j.renene.2016.02.068

5. Dalrymple OK, Halfhide T, Udom I, et al. Wastewater use in algae production for generation of renewable resources : a review and preliminary results. Saline Systems. 2013;9(1):1.

doi:10.1186/2046-9063-9-2 
6. Suali E, Sarbatly R. Conversion of microalgae to biofuel. Renew Sustain Energy Rev. 2012;16(6):4316-4342. doi:10.1016/j.rser.2012.03.047

7. Ramachandran K, Suganya T, Gandhi NN, Renganathan S. Recent developments for biodiesel production by ultrasonic assist transesterification using different heterogeneous catalyst : A review. Renew Sustain Energy Rev. 2013;22:410-418. doi:10.1016/j.rser.2013.01.057

8. Thangaraj B, Solomon PR, Muniyandi B, Ranganathan S, Lin L. Catalysis in biodiesel production — a review. Clean Energy. 2019;3(1):2-23. doi:10.1093/ce/zky020

9. Mukenga M, Muzenda E, Jalama K, Meijboom R. Biodiesel Production from Soybean Oil over TiO2 Supported nano-ZnO.World academy of Science, Engineering and Technology International Journal of Chemical, Molecular, Nuclear, Materials and Metallurgical Engineering 2012;2028:949-953.

10. Alba-Rubio AC, Santamaría-González J, Mérida-Robles JM, et al. Heterogeneous transesterification processes by using $\mathrm{CaO}$ supported on zinc oxide as basic catalysts. Catal Today. 2010;149(3-4):281-287. doi:10.1016/j.cattod.2009.06.024

11. Yoo SJ, Lee H shik, Veriansyah B, Kim J, Kim JD, Lee YW. Synthesis of biodiesel from rapeseed oil using supercritical methanol with metal oxide catalysts. Bioresour Technol. 2010;101(22):8686-8689. doi:10.1016/j.biortech.2010.06.073

12. Refaat AA. Biodiesel production using solid metal oxide catalysts. Int J Environ Sci Technol. 2011;8(1):203-221. doi:10.1007/BF03326210

13. Zabeti M, Wan Daud WMA, Aroua MK. Activity of solid catalysts for biodiesel production: A review. Fuel Process Technol. 2009;90(6):770-777. doi:10.1016/j.fuproc.2009.03.010

14. Chouhan APS, Sarma AK. Modern heterogeneous catalysts for biodiesel production: A comprehensive review. Renew Sustain Energy Rev. 2011;15(9):4378-4399. doi:10.1016/j.rser.2011.07.112

15. Ngamcharussrivichai $\mathrm{C}$, Totarat $\mathrm{P}$, Bunyakiat $\mathrm{K}$. Ca and Zn mixed oxide as a heterogeneous base catalyst for transesterification of palm kernel oil. Appl Catal A Gen. 2008;341(1-2):77-85. doi:10.1016/j.apcata.2008.02.020

16. Kesic Z, Lukic I, Zdujic M, Liu H, Skala D. Mechanochemically synthesized CaO ZnO catalyst for biodiesel production. Procedia Eng. 2012;42(August):1169-1178. doi:10.1016/j.proeng.2012.07.509

17. Makareviciene V, Skorupskaite V. Transesterification of Microalgae for Biodiesel Production. Elsevier Inc.; 2019. doi:10.1016/b978-0-12-815162-4.00017-3 
18. Malpani M, Varma AK, Mondal P. Production of bio-oil from algal biomass and its upgradation to biodiesel using CaO-based heterogeneous catalysts. Int J Green Energy. 2016;13(10):969976. doi:10.1080/15435075.2015.1088445

19. Manikandan G, Rajasekaran R. TRANSESTERIFICATION OF ALGAL OIL USING NANO CaO. Int. J. Chem. Sci. 2013;11(1):591-597.

20. Ma G, Hu W, Pei H, Jiang L, Song M, Mu R. In situ heterogeneous transesterification of microalgae using combined ultrasound and microwave irradiation. Energy Convers Manag. 2015;90:41-46. doi:10.1016/j.enconman.2014.10.061

21. Narula V, Khan MF, Negi A, Kalra S, Thakur A, Jain S. Low temperature optimization of biodiesel production from algal oil using $\mathrm{CaO}$ and $\mathrm{CaO} / \mathrm{Al} 2 \mathrm{O} 3$ as catalyst by the application of response surface methodology. Energy. 2017;140:879-884. doi:10.1016/j.energy.2017.09.028

22. Fangrui M, Milford H. Biodiesel production: A review. Bioresour Technol. 1999;70(1):1-15. doi:10.1016/S0960-8524(99)00025-5

23. Shwetharani R, Balakrishna RG. Efficient algal lipid extraction via photocatalysis and its conversion to biofuel. Appl Energy. 2016;168:364-374. doi:10.1016/j.apenergy.2016.01.087

24. $\mathrm{Wu} \mathrm{JM}$, Chen YR. Ultraviolet-light-assisted formation of $\mathrm{ZnO}$ nanowires in ambient air: Comparison of photoresponsive and photocatalytic activities in zinc hydroxide. J Phys Chem C. 2011;115(5):2235-2243. doi:10.1021/jp110320h

25. Quirino MR, Oliveira MJC, Keyson D, Lucena GL, Oliveira JBL, Gama L. Synthesis of zinc oxide by microwave hydrothermal method for application to transesterification of soybean oil (biodiesel). Mater Chem Phys. 2017;185:24-30. doi:10.1016/j.matchemphys.2016.09.062

26. Kumar SS, Venkateswarlu P, Rao VR, Rao GN. Synthesis, characterization and optical properties of zinc oxide nanoparticles. Int Nano Lett. 2013;3(1):30. doi:10.1186/2228-5326-3-30

27. Udayabhaskar R, Mangalaraja R V., Karthikeyan B. Thermal annealing induced structural and optical properties of Ca doped ZnO nanoparticles. J Mater Sci Mater Electron. 2013;24(9):31833188. doi:10.1007/s10854-013-1225-Z 